\title{
An autobiographic conversation with Roger D Kornberg on his work on transcription regulation
}

\author{
RD Kornberg \\ Cell Death and Differentiation (2007) 14, 1977-1980; doi:10.1038/sj.cdd.4402250
}

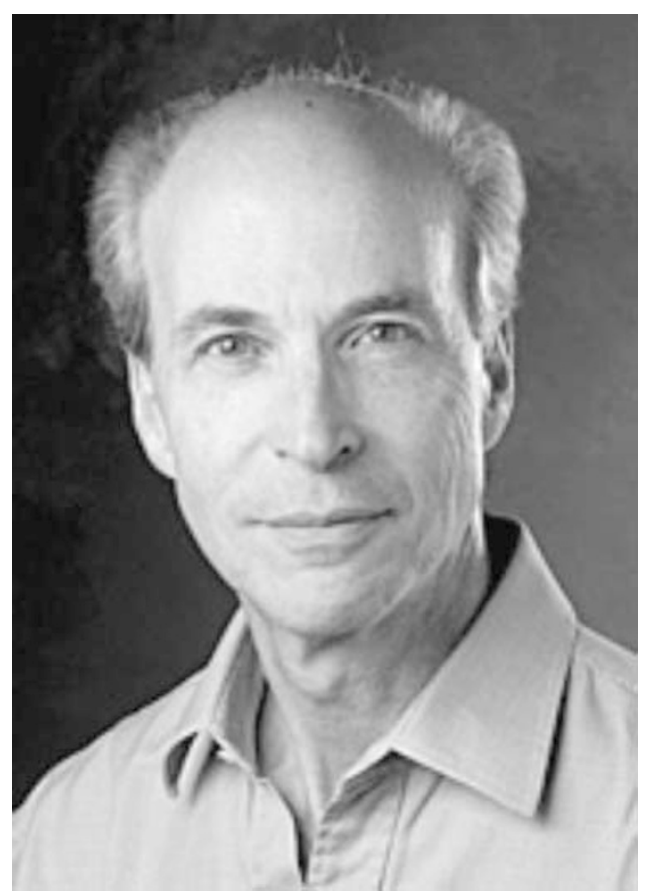

\section{Roger D Kornberg}

Thanks to the Nobel Foundation (Copyright ${ }^{\odot}$ The Nobel Foundation 2006) Dr Kornberg shares his autobiography with us

My adult scientific career began with graduate study in chemical physics with Harden McConnell at Stanford. I had the idea of elucidating the mechanism of ion transport across biological membranes by nuclear resonance. I thought ion transport must involve rotation of the transport protein in the membrane. Struggling to prove this wrong idea, it occurred to me to study the rotation in the membrane of a lipid molecule, about 1000 molecular weight, rather than a protein 50 times larger. This led to my discoveries, by nuclear and paramagnetic resonance methods, of phospholipid flip-flop, an exceedingly slow process, and lateral diffusion, exceedingly fast. ${ }^{1,2}$

For postdoctoral work, I wanted to learn about the other important method of physicochemical analysis of macromolecules, X-ray diffraction. The obvious choice was the Laboratory of Molecular Biology (LMB) in Cambridge, where protein crystallography was developed and still most intensively practiced at the time. I went in the spring of 1972 to work with Aaron Klug, who was not only a leading crystallographer, but also responsible for the application of Fourier methods to electron microscopy and image processing. While looking for a problem to study by X-ray diffraction, I got to know Mark Bretscher, the only person at the LMB interested in membrane structure, and he suggested reading a paper just published by Francis Crick titled 'A General Model for Higher Organism Chromosomes'. ${ }^{3}$ Figure 3 of that paper was a diagram showing a loop of DNA crossed by a dashed line, said to symbolize a histone molecule. When I raised the subject with Aaron Klug, he immediately produced a sheaf of papers on the X-ray analysis of chromosomal material, or 'chromatin,' known for nearly a century to contain roughly equal weights of histones and DNA. Aaron had discussed the interpretation of the X-ray pattern of chromatin extensively with Francis, and he encouraged me to pursue the problem. He warned me, however, that it was a 'messy' problem.

Notorious might have been a better word. Many had succumbed to the allure of the problem, with its potential for insight into genetic chemistry, only to be frustrated by the intractability of the histones. These proteins were, on the one hand, surprisingly simple, and on the other hand, hopelessly complicated. There are only five types of histone, designated $\mathrm{H} 1, \mathrm{H} 2 \mathrm{~A}, \mathrm{H} 2 \mathrm{~B}, \mathrm{H} 3$, and $\mathrm{H} 4$. Upon isolation, however, the individual histones proved to be extraordinarily sticky, binding avidly to DNA and interacting with one another in every possible combination. Whereas the X-ray diffraction pattern of chromatin was indicative of repeating order, the biochemical behavior of the histones did not appear to explain it. There was, moreover, sufficient variation in the relative amounts of the histone types in various tissues and organisms to make the idea of a unique repeating order untenable'. ${ }^{4}$ The histones

From Les Prix Nobel. The Nobel Prizes 2006, Editor Karl Grandin (Nobel Foundation), Stockholm, 2007 Copyright ${ }^{\complement}$ The Nobel Foundation 2006

The Nobel Prize in Chemistry 2006

Correspondence: G Melino, Cell death and Differentiation, Rome Editorial Office, D26, University Rome Tor Vergata, via Montpellier 1, 00133-Rome, Italy.

E-mail: cell.death.differ@uniroma2.it 
came to be regarded as a kind of amorphous glue, coating the chromosomal DNA, with no obvious significance.

I began by repeating the work of others, isolating the individual histones, mixing them in various combinations with DNA, and recording X-ray diffraction patterns. I also scoured the literature and came across two papers that influenced my thinking. A paper by Hewish and Burgoyne reported the cleavage of about $10 \%$ of chromosomal DNA by an endogenous nuclease in isolated rat liver nuclei to multiples of a unit size. ${ }^{5}$ When I mentioned this to Francis Crick, he shot off a letter to Hewish inquiring about the size. The reply came from Burgoyne, giving the sedimentation coefficient of the unit length of DNA. Assuming the measurement was made under alkaline conditions, as was customary for sedimentation analysis of RNA, much studied at the LMB at the time, the value from Burgoyne corresponded to about 500 bases. This unit size did not relate to any other information about chromatin, and the appearance of multiples of the unit size simply confirmed what we already knew from $X$-ray diffraction, that chromatin contained some amount of repeating substructure.

The second paper, by van der Westhuyzen and von Holt, reported the extraction of histones from chromatin by mild methods, rather than with strong acid or other harsh treatment, as was customary at the time. ${ }^{6}$ Mild methods failed to resolve the histones entirely from one another, so the paper was ignored. What attracted my attention was the clean separation of the mildly extracted histones into two groups, $\mathrm{H} 2 \mathrm{~A} / \mathrm{H} 2 \mathrm{~B}$ and $\mathrm{H} 3 / \mathrm{H} 4$. This separation contrasted with the promiscuous interactions of the histones observed previously. I realized this promiscuity was likely attributable to the denaturation of histones during isolation in the past. From the data in the paper, I could also deduce that the $\mathrm{H} 3 / \mathrm{H} 4$ group behaved as if twice the size of the $\mathrm{H} 2 \mathrm{~A} / \mathrm{H} 2 \mathrm{~B}$ group, although all four individual histone proteins were about the same size. I concluded that $\mathrm{H} 3$ and $\mathrm{H} 4$ must form a dimer, and I thought I might crystallize and solve the structure of this unique histone oligomer.

What followed was truly astounding. I measured the molecular weight of the purified $\mathrm{H} 3 / \mathrm{H} 4$ preparation by equilibrium ultracentrifugation, while Jean Thomas offered to analyze the material by chemical cross-linking. Both methods showed unequivocally that $\mathrm{H} 3$ and $\mathrm{H} 4$ were in the form of a double dimer, an $(\mathrm{H} 3)_{2}(\mathrm{H} 4)_{2}$ tetramer. ${ }^{7}$ I pondered this result for days, and came to the following conclusions. ${ }^{8}$ First, the exact equivalence of $\mathrm{H} 3$ and $\mathrm{H} 4$ in the tetramer implied that the differences in relative amounts of the histones from various sources measured in the past must be due to experimental error. This and the stoichiometry of the tetramer implied a unit of structure in chromatin based on two each of the four histones, or an $(\mathrm{H} 2 \mathrm{~A})_{2}(\mathrm{H} 2 \mathrm{~B})_{2}(\mathrm{H} 3)_{2}(\mathrm{H} 4)_{2}$ octamer. Second, since chromatin from all sources contains roughly one of each histone for every $100 \mathrm{bp}$ of DNA, a histone octamer would be associated with $200 \mathrm{bp}$ of DNA. Finally, the $(\mathrm{H} 3)_{2}(\mathrm{H} 4)_{2}$ tetramer was reminiscent of hemoglobin, an $\alpha_{2} \beta_{2}$ tetramer. The $\mathrm{X}$-ray structures of hemoglobin and other oligomeric proteins available at the time were compact, with no holes through which a molecule the size of DNA might pass. Rather, the DNA in chromatin must be wrapped on the outside of the histone octamer.
As I turned these ideas over in mind, it struck me how I might explain the results of Hewish and Burgoyne. What if their sedimentation coefficient of unit length DNA fragments was measured under neutral rather than alkaline conditions? Then the DNA would have been double stranded and about $250 \mathrm{bp}$ in length. Allowing for the approximate nature of the result, the correspondence with my prediction of 200 bp was electrifying. Then I recalled a reference near the end of the Hewish and Burgoyne paper to a report of a similar pattern of DNA fragments by Williamson. I rushed to the library and found that Williamson had obtained a ladder of DNA fragments from the cytoplasm of necrotic cells and measured the unit size by sedimentation under neutral conditions: the result was $205 \mathrm{bp}$ ! I was euphoric. In the months and years to follow, it was often pointed out how thin was the support for my ideas and how extended the line of reasoning, but I never really doubted the conclusions. The prediction of the DNA unit size and its verification convinced me completely.

Support for a particulate substructure of chromatin came from electron microscopy and from nuclease digestion and sedimentation analysis. Some work on these lines was done even before my own, and though not definitive, was nicely coincident with my ideas. In the years to follow, with colleagues in Cambridge, I proved the existence of the histone octamer and the equivalence of the $200 \mathrm{bp}$ unit with the particle seen in the electron microscope. ${ }^{9}$ This chapter of the chromatin story concluded with the X-ray crystal structure determination of the particle, now known as the nucleosome, showing a histone octamer surrounded by DNA, in near atomic detail. ${ }^{10}$

At this natural break in the work, I returned to the US, first as faculty member of the Department of Biological Chemistry of Harvard Medical School in 1976, and then the Department of Structural Biology of Stanford Medical School in 1978. I had decided to pursue the function rather than the structure of the nucleosome, and was joined in this by Yahli Lorch, who became my lifelong partner in chromatin research, and also my partner in life. We investigated the consequences of the nucleosome for transcription. It was believed that histones are generally inhibitory to transcription. We found, to the contrary, that RNA polymerases are capable of reading right through a nucleosome. Coiling of promoter DNA in a nucleosome, however, abolished initiation by RNA polymerase II (pol II). ${ }^{11}$ This finding, together with genetic studies of Michael Grunstein and colleagues, identified a regulatory role of the nucleosome in transcription. It has since emerged that nucleosomes play regulatory roles in a wide range of chromosomal transactions. A whole new field has emerged, one of the most active in bioscience today. It involves a bewildering variety of post-translational modifications of the histones, and a protein machinery of great complexity for applying, recognizing, and removing these modifications.

Although Yahli's first priority was the rearing of our children, Guy, Maya, and Gil, she performed a series of important studies of chromatin remodeling, believed to oppose inhibition by nucleosomes. She began with Brad Cairns, who discovered the RSC chromatin remodeling complex. Subsequent work showed that RSC disrupts nucleosome structure and slides histone octamers along the DNA. ${ }^{12,13}$ Most recently, we found that RSC can transfer a histone octamer to a histone 
chaperone protein, exposing the nucleosomal DNA for transactions such as transcription. ${ }^{14}$

For studies of transcriptional regulation, it was necessary to identify the transcription machinery. Biochemical work, in the laboratories of Robert Roeder, Ronald and Joan Conaway, and others, revealed the complexity of the RNA pol II transcription machinery of mammalian cells, and it was apparent there was much to be gained by studies in yeast. A combined genetic and biochemical approach, possible only in yeast, would be advantageous for the solution of such a difficult problem. There was, however, a major obstacle. The development of a yeast pol II transcription system had been attempted unsuccessfully in many laboratories for more than a decade. Efforts to develop biochemical systems from yeast for RNA splicing, membrane transport, and other processes had also met with failure, leading to the widely held view that yeast, although the organism of choice for eukaryotic genetic analysis, was unsuited to biochemical investigation. First Yahli, and then graduate student Neal Lue, took up the challenge. Neal was eventually successful, by changing a number of procedures and conditions used in the past, including the replacement of chloride by acetate ion. ${ }^{15}$ Remarkably, chloride, though a component of other transcription systems, is highly inhibitory to yeast pol II transcription.

Neal, Ray Kelleher, and Peter Flanagan undertook fractionation of the yeast system, followed by Mike Sayre, John Feaver, Herbert Tschochner, Opher Gileadi, and Lynn Henry. The yeast system was problematic, since the starting transcription signal was a 1000-fold less than that in mammalian systems, and we soon reached an impasse. After enriching the transcription proteins about a 100 -fold through two chromatographic steps, we could proceed no further. Every subsequent step eliminated transcription completely. Mike achieved a breakthrough by starting over. He realized the problem was the loss of essential components and an accumulation of inhibitors, and he devised a new fractionation procedure that was ultimately successful. ${ }^{16}$

An important outcome of this work was the discovery that yeast and mammalian pol II systems are the same. Differences in promoter structure believed to reflect fundamental differences in the transcription proteins proved to be insignificant. The real payoff, however, was in the study of transcriptional regulation. In the late 1980s, it was thought the communication between gene activator proteins and the transcription machinery was direct. In 1990 and 1991, Ray and Peter produced evidence for an additional factor required for this communication in a still crude yeast system. ${ }^{17,18}$ This additional factor, which we referred to as Mediator, proved elusive. The requirement for the factor was variable over the course of fractionation. As so often happens, the solution of the problem came from an unexpected direction. The most difficult protein of the pol II transcription system to purify, known as factor $\mathrm{IIH}$, was contaminated with Mediator, and only after entirely pure IIH was obtained by Jesper Svejstrup ${ }^{19}$ were Stefan Björklund and Young-Joon Kim then able to complete the isolation of Mediator. ${ }^{20}$ To our astonishment, pure Mediator proved to be an assembly of nearly two dozen proteins, more than half of which were known from genetic studies in yeast to be involved in transcriptional regulation.
In parallel with these biochemical studies of pol II transcription, we pursued the structure of the transcription machinery. Pol II, the central component of the machinery, is an assembly of a dozen proteins, several times the size of any asymmetric structure determined by $\mathrm{X}$-ray diffraction in the early 1980s when we began. The story of our solution of the pol II problem is told in my Nobel Lecture, except for its origins in my graduate studies of lipid diffusion. While I was in Cambridge, Aaron Klug and collaborators were developing electron microscope crystallography for the solution of protein structures too large for X-ray crystallography. As the name implies, the electron microscope approach also requires protein crystals, only they must be thin, preferably a single protein molecule thick, or 'two-dimensional,' for transmission of the electron beam. The work in Cambridge at the time was limited to naturally occurring ordered arrays of proteins, and it was apparent that a general method of forming two-dimensional crystals was needed to bring any protein of interest within reach of the electron microscope procedure. I thought I might exploit lateral diffusion in lipid layers for the purpose. A protein bound to a lipid layer would be constrained in two dimensions but free to diffuse and, I hoped, to crystallize. I tried this idea, beginning with nucleosomes and positively charged lipid layers. Finally, after repeated failures over a period of about 5 years, a sabbatical visitor, Ed Uzgiris, was successful, with the combination of a monoclonal antibody directed against a lipid hapten. ${ }^{21}$ This work led eventually to two-dimensional crystals of pol II, and then to large single crystals and the X-ray structure of pol II.

Our biochemical and crystallographic work converged in the $\mathrm{X}$-ray structure determination of pol II. This convergence was the culmination of a long effort, but also a beginning. Pol II associates with two dozen additional transcription proteins and with Mediator in a giant assembly formed at every promoter prior to the initiation of transcription. The ultimate goal of our work is to solve this giant complex and thus to understand the mechanism and regulation of transcription. We believe we will achieve this goal within the next decade, through crystallography and, possibly, another development in electron microscopy. Inspired by graduate student Grant Jensen, we have pursued the synthesis of large heavy atom clusters, for the purpose of structure determination without crystals at near atomic resolution. ${ }^{22}$ This work has opened a window on a whole new realm of inorganic chemistry and materials science, through which we may pass into the future.

1. Kornberg RD, McConnell HM. Inside-outside transitions of phospholipids in vesicle membranes. Biochemistry 1971a: 10: 1111-1120.

2. Kornberg RD, McConnell HM. Lateral diffusion of phospholipids in a vesicle membrane. Proc Natl Acad Sci USA 1971b; 68: 2564-2568.

3. Crick F. General model for the chromosomes of higher organisms. Nature 1971; 234: 25-27.

4. Huberman JA. Structure of chromosome fibers and chromosomes. Annu Rev Biochem 1973; 42: 355-378.

5. Hewish DR, Burgoyne LA. Chromatin sub-structure. The digestion of chromatin DNA at regularly spaced sites by a nuclear deoxyribonuclease. Biochem Biophys Res Commun 1973; 52: 504-510.

6. van der Westhuyzen DR, von Holt C. A new procedure for the isolation and fractionation of histones. FEBS Lett 1971; 14: 333-337.

7. Kornberg RD, Thomas JO. Chromatin structure; oligomers of the histones. Science 1974; 184: 865-868.

8. Kornberg RD. Chromatin structure: a repeating unit of histones and DNA. Science 1974; 184: 868-871. 
9. Kornberg RD. Structure of chromatin. Ann Rev Biochem 1977; 46: 931-954.

10. Luger K, Mader AW, Richmond RK, Sargent DF, Richmond TJ. Crystal structure of the nucleosome core particle at 2.8 A resolution. Nature 1997; 389: 251-260.

11. Lorch Y, LaPointe JW, Kornberg RD. Nucleosomes inhibit the initiation of transcription but allow chain elongation with the displacement of histones. Cell 1987; 49: 203-210.

12. Lorch Y, Cairns BR, Zhang M, Kornberg RD. Activated RSC-nucleosome complex and persistently altered form of the nucleosome. Cell 1998; 94: 29-34.

13. Lorch Y, Zhang M, Kornberg RD. RSC unravels the nucleosome. Mol Cell 2001; 7: 89-95.

14. Lorch Y, Maier-Davis B, Kornberg RD. Chromatin remodeling by nucleosome disassembly in vitro. Proc Natl Acad Sci USA 2006; 103: 3090-3093.

15. Lue NF, Kornberg RD. Accurate initiation at RNA polymerase II promoters in extracts from Saccharomyces cerevisiae. Proc Natl Acad Sci USA 1987; 84: 8839-8843.

16. Sayre MH, Tschochner H, Kornberg RD. Reconstitution of transcription with five purified initiation factors and RNA polymerase II from Saccharomyces cerevisiae. J Biol Chem 1992; 267: 23376-23382.
17. Kelleher IRJ, Flanagan PM, Kornberg RD. A novel mediator between activator proteins and the RNA polymerase II transcription apparatus. Cell 1990; 61: 1209-1215.

18. Flanagan PM, Kelleher III RJ, Sayre MH, Tschochner H, Kornberg RD. A mediator for activation of RNA polymerase II transcription in vitro. Nature 1991; 350: 436-438.

19. Svejstrup JQ, Wang Z, Feaver WJ, Wu X, Bushnell DA, Donahue TF et al. Different forms of TFIIH for transcription and DNA repair: Holo-TFIIH and a nucleotide excision repairosome. Cell 1995; 80: 21-28.

20. Kim YJ, Björklund S, Li Y, Sayre MH, Kornberg RD. A multiprotein mediator of transcriptional activation and its interaction with the C-terminal repeat domain of RNA polymerase II. Cell 1994; 77: 599-608.

21. Uzgiris $\mathrm{EE}$, Kornberg RD. Two-dimensional crystallization technique for imaging macromolecules, with an application to antigen-antibody-complement complexes. Nature 1983; 301: 125-129.

22. Jensen GJ, Kornberg RD. Single-particle selection and alignment with heavy atom cluster-antibody conjugates. Proc Natl Acad Sci USA 1998; 95: 9262-9267. 